\title{
Clinical Audits in Chronic Obstructive Pulmonary Disease: what for?
}

Jose Luis Lopez-Campos, MD, Maria Abad Arranz, MD and Laura Carrasco Hernández, MD

Unidad Médico-Quirúrgica de Enfermedades Respiratorias, Instituto de Biomedicina de Sevilla (IBIS), Hospital Universitario Virgen del Rocío, Universidad de Sevilla, Sevilla, Spain; Centro de Investigación en Red de Enfermedades Respiratorias (CIBERES), Instituto de Salud Carlos III (ISCIII), Madrid, Spain

\section{ABSTRACT}

The complexity of healthcare and the rapid and constant changes in technology and therapies for chronic obstructive pulmonary disease (COPD) may generate uncertainty in decision-making and variability in clinical practice. Currently, there is a gap between the medical care that patients receive and the recommended practice. In both primary and secondary care, there are unjustified variations in practice and outcomes, which cannot be explained by the characteristics of the patients. Clinical audits emerge as an overarching tool that allows a constantly updating process that feeds back with the aim of improving healthcare. The objective of this review is to update the clinical audits for COPD as an available tool with a potential to improve healthcare. Clinicians and health managers should work hand in hand to overcome current limitations and be able to give the best possible clinical care for patients with COPD. (BRN Rev. 2019;5(2):120-134) Corresponding author: J.L. Lopez-Campos, Icampos@separ.es

Key words: Chronic obstructive pulmonary disease. Clinical audit. Health management. Quality of care. 


\section{INTRODUCTION}

The evaluation of the clinical activity aimed at healthcare improvement should be part of the daily clinical work. However, the training received by attending physicians in quality of care of care remains scant. This statement is particularly relevant when it comes to chronic, serious diseases with a profound impact on patients' lives, their families or the health system. In this sense, chronic obstructive pulmonary disease (COPD) is a first-magnitude disease in terms of morbidity and mortality ${ }^{1}$, with a wide prevalence in the population ${ }^{2}$ and a significant impact on the health sys$t^{3} \mathrm{~m}^{3,4}$. Therefore, the healthcare of the patient with COPD should take advantage of the highest quality standards ${ }^{5}$ aiming for improvement of the clinical outcomes.

\section{FACTORS ASSOCIATED WITH CLINICAL OUTCOMES}

To understand the importance of the evaluation of the quality of care in COPD, it is necessary to review which are the main variables that are associated with clinical outcomes. As physicians, we can easily come up with various relevant clinical variables that can be divided from an academic perspective into three main domains. Firstly, some variables are related to the characteristics of the patients and their style of living. Important aspects such as age, sex, genome, toxic habits or even their personality are vital factors that will condition health outcomes. Regarding COPD, there is a considerable number of studies reporting the importance of these factors: the prevalence of the disease has been associated with age and sex $^{6}$; sex differences in symptoms perception and prognosis have also been discussed ${ }^{7}$; diet has also been pointed out as related to $\mathrm{COPD}^{8-10}$; and, genome and the presence of certain polymorphisms have been associated with different clinical outcomes ${ }^{11,12}$.

Secondly, disease-related variables and their impact on health outcomes are also relevant. Among these factors we can mention the severity of a particular case, its progression over time or the onset of complications. In COPD, there is considerable information indicating the importance of disease-related variables with clinical outcomes alone or in combination ${ }^{14-16}$. Furthermore, lung function trajectories from the early years have also been reported to be of interest ${ }^{13}$.

Finally, a third group of variables are probably social and environmental aspects. Factors such as social or family support and the potential impact of the disease on social behaviour or environmental exposures would be equally important in relation to health outcomes. For instance, occupational exposures are relevant in the progression of the disease in $\mathrm{COPD}^{17}$ and indoor and outdoor pollution have been related to different COPD-associated outcomes ${ }^{18-19}$.

Altogether, these three aspects, i.e. patient characteristics and lifestyle, disease features and social and environmental determinants, are clearly associated with the clinical outcomes in COPD. Of note, all these factors do not act on their own but interact with each other to influence the final result. Additionally, there are two other aspects to consider: the availability of resources and the organisation of care are also strongly associated with clinical outcomes. The supporting evidence is extensive and we can mention three examples. A study 
that evaluated discharge records from 1999 to 2008 for 208 Californian hospitals aimed to determine the association between hospital spending and risk-adjusted inpatient mortality for each of the six following diagnoses at admission: acute myocardial infarction, congestive heart failure, acute stroke, gastrointestinal haemorrhage, hip fracture, and pneumonia ${ }^{20}$. It was shown that patients admitted to hospitals in the highest quintile of hospital spending had lower inpatient mortality than those admitted to hospitals in the lowest quintile. Another study from the University of California used data from a large tertiary academic medical centre involving 197,961 admissions and 176,696 nursing shifts of 8 hours each in 43 hospital units to assess the association between mortality and patient exposure to nursing shifts ${ }^{21}$. The authors found that a higher proportion of hours of nursing care provided by registered nurses was associated with better care for hospitalised patients. Finally, using data from the 2016 Global Burden of Disease (GBD) study, another analysis showed the mortality map due to low-quality health systems (Fig. 1)22. According to this figure, poor-quality healthcare contributed to the most deaths per unit population in South Asia and Central and West Africa. Using data from the 2016 GBD study, the authors were able to estimate that total low- and middle-income countries poor-quality mortality was 82 deaths per 100,000 population.

Importantly, the last group of variables associated with clinical outcomes is directly related to clinical practice. It has been pointed out that the way we deliver care as healthcare professionals also plays a key role. Notably, the complexity of healthcare itself and the rapid and constant changes in technology and therapies may generate uncertainty in decision-making and may end up determining different forms of clinical practice. Currently, there is extensive evidence that there is a gap between the medical care that patients receive and the recommended practice. In both primary and secondary care, there are unjustified variations in practice and outcomes, which cannot be explained by the characteristics of patients. In COPD, this phenomenon has been clearly shown after the results of various clinical audits ${ }^{23-26}$. The Clinical Audit of Patients Admitted to Hospital in Spain due to Exacerbation of COPD (AUDIPOC Study) identified large between-hospital variations in care and clinical outcomes ${ }^{27}$. The authors evaluated all different potential explanatory variables and found that variables representing patients' clinical conditions were stronger predictors of clinical outcomes than resources and organisation of care variables.

To make things more complex, AUDIPOC demonstrated a noteworthy reduction in the observed crude between-hospital variation in outcomes after accounting for the so-called hospital-cluster effect. This cluster effect indicates that patients with similar characteristics may experience different processes of care and outcomes, depending on the hospital to which they are admitted because they are subject to distinct common contextual influences $^{28}$. The cluster effect acknowledges that all patients admitted to any given hospital for a specific clinical issue would get similar care, which might in turn be different from those delivered by another institution. This phenomenon may be explained by the existence of specific hospital-linked factors. Such variables may include, but are not limited to, socioeconomic status, demographics, 


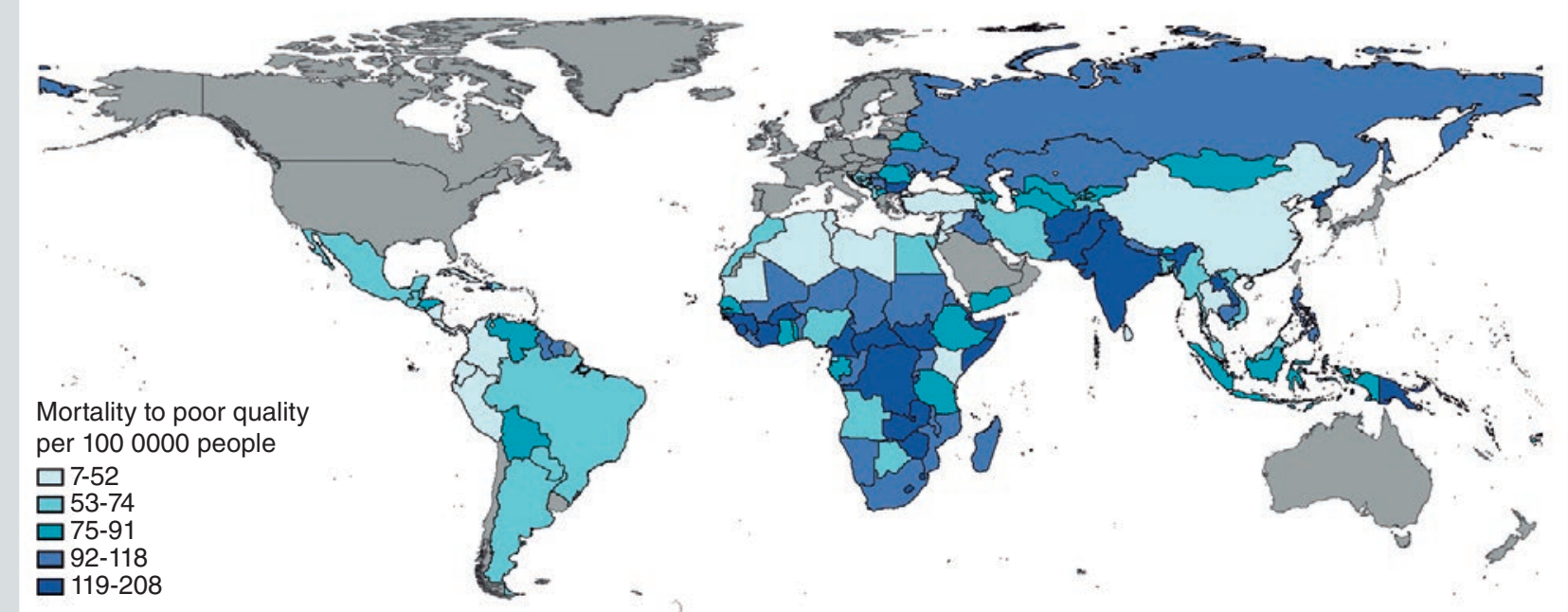

Figure 1. Mortality due to poor-quality healthcare by country (reproduced from Kruk ME et al.22, http://dx.doi.org/10.1016/S01406736(18)31668-4, available under the terms of the HYPERLINK http://creativecommons.org/licenses/by/4.0/ (CC BY). No modification of the original figure has been made).

environmental characteristics, usage of health services and clinical practice styles. Therefore, such differences among distinct participating hospitals (i.e. cluster effect) might exert a significant influence on outcomes.

\section{HOW TO DEAL WITH CLINICAL PRACTICE VARIABILITY?}

From the arguments alluded to, we can surmise that the variability of clinical practice is considerable and that the number, types and levels of the variables that might explain this variability are enormous. Accordingly, there is a need for tools that allow the control of this variability in the context of the clinical circumstances with the final aim to provide a more uniform clinical practice adapted to the concrete needs depending on the setting and circumstances.

The generation of clinical practice guidelines showing recommendations for clinical practice with the perspective of evidence-based medicine constitutes one of these initiatives that contributes to the improvement of the quality and the equity of healthcare. Evidence-based medicine aims to ensure that clinical decisions are made on the basis of the most up-to-date, solid, reliable, and available scientific evidence. The advantages of this approach are obvious: evidence-based practice allows us to search the best available treatment for our patients, to optimise the decisions through our clinical judgement, generate and demand continuous investigation, confer protection against lawsuits, and base decisions on substantiated scientific data ${ }^{29}$. However, a number of limitations have been pointed out: evidence-based practice may denigrate clinical judgment, it does not apply to care of individual patients, advocates a slavish, "cook-book" approach to treatment, ignores patient's values and preferences, and requires solid data to make decisions; therefore, if there is no data, no recommendations can be given 29,30 . 
Another approach is the management by the so-called integrated healthcare processes. This is a form of clinical management that coordinates health resources to generate integrated care pathways, aiming to achieve an integrated care with a longitudinal and continuous view $^{31}$. Although the approach may result convenient and logical for reducing the variability, the process of implementation of the different policies diverges in practice, with three main limitations: 1 ) the limited use of power to resist to change, 2) the unstable level of internal communication among the professionals involved, and 3) the poor learning process by both the professionals and policy makers ${ }^{32,33}$.

In this context, the Chronic Care model ${ }^{34}$ is widely accepted as a conceptual framework to effectively address the burden of non-communicable diseases, with integrated care services being one of its core components. Again, the practical deployment and extensive adoption of integrated care remain a challenge. In this regard, a recent study showed high potential to enhance health outcomes with cost-containment for four articulated integrated care services supported by information technologies, namely home-based long-term maintenance of rehabilitation effects, enhanced care for frail patients, home hospitalisation and early discharge, and support for remote diagnosis in primary care.

\section{CLINICAL AUDITS IN CHRONIC OBSTRUCTIVE PULMONARY DISEASE: WHAT FOR?}

In this context, clinical audits emerge as a tool to improve healthcare ${ }^{36,37}$. According to the World Health Organization, a clinical audit is a quality improvement process that seeks to improve patient care and outcomes through systematic review of care against explicit criteria and the implementation of change ${ }^{38}$. Far from merely being a systematised procedure for retrospective recovery of clinical data and the available resources for evaluating professional performance and associated factors, clinical audits are a process of continuous improvement in healthcare by evaluating the health system and its professionals. Analogously to the Plan-Do-Check-Act (PDCA) Deming cy$\mathrm{cle}^{39}$, a cycle of the clinical audit can be defined (Fig. 2) ${ }^{38}$. Therefore, although not exempted from methodological considerations that may need an adaptation to each specific clinical context, clinical audits are presented as a collaborative working tool that seeks to collect information with the idea of showing this information to the audited professionals, so that it serves to improve healthcare.

\section{CLINICAL AUDITS IN CHRONIC OBSTRUCTIVE PULMONARY DISEASE: SOME KEY FINDINGS}

As alluded to above, there is a clear need to perform clinical audits in a disease such as COPD. Epidemiological data of the disease places it as a first-magnitude disease. With a prevalence of around $10 \%{ }^{2,6}$, on the rise ${ }^{40}$, and with a considerable mortality ${ }^{41,42}$ and impact on sanitary budgets with direct costs ranging from 504 \$/patient/year to 9,981 \$/patient/ year in different countries ${ }^{43}$, COPD has become a world health problem.

Until recently, clinical audits for COPD were not frequently carried out. Over the last few decades, the United Kingdom ${ }^{4}$, followed by 


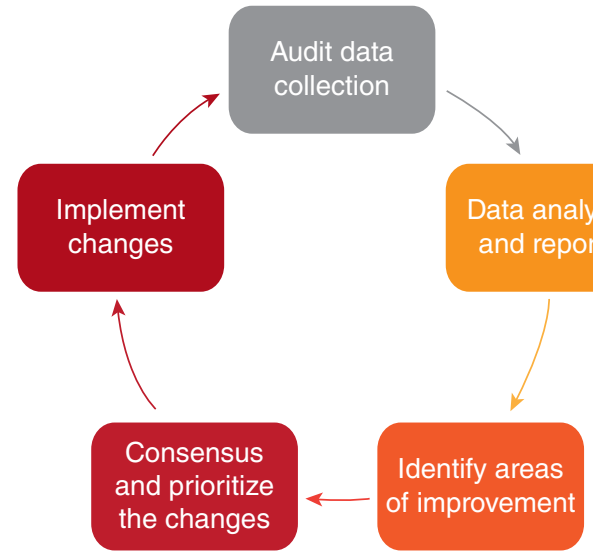

Figure 2. The audit cycle.

Spain ${ }^{45,46}$, has been leading the audit process for COPD in Europe. Additionally, several countries have started their own audit projects ${ }^{47,49}$, such as the European COPD Audit in 13 European countries $^{50,51}$ (Fig. 3). In Spain, the AUDIPOC network evaluated clinical care in patients hospitalised due to $\mathrm{COPD}^{27}$ and recent initiatives have explored the clinical performances in specialised respiratory outpatient clinics ${ }^{26}$. These audits have provided valuable information about medical interventions in hospital wards for patients admitted for COPD exacerbation ${ }^{51}$, the resources available ${ }^{52}$, and the interrelationship between resources and clinical practice ${ }^{26,27}$. Additionally, clinical audits in primary care are starting to emerge providing valuable data on how to improve clinical care ${ }^{24,53}$. To review in detail all the data obtained as a consequence of these audits would be long and complex. However, it might be appropriate to review some of the most relevant messages from these clinical settings.

\section{Clinical audits during chronic obstructive pulmonary disease admissions}

During the admissions, the European COPD Audit provided relevant information on clinical practice. The distribution by sex depicted a picture of male predominance. However, the United Kingdom was the one country in which the number of women admitted due to COPD exacerbation over exceeded the number of men (Fig. 4A). This is probably reflecting the initiation of the COPD epidemics in women expected to come in the next few coming years due to the incorporation of women to tobacco smoking ${ }^{54}$.

Another key relevant aspect was the number of current smokers. According to the European COPD Audit data, 33\% of those admitted for COPD exacerbation still continued to smoke at the time of admission (Fig. 4B). This finding is striking since we are talking about a disease directly related to tobacco use and in a clinical situation of exacerbation severe enough to be admitted to the hospital. Notwithstanding, a considerable number of cases were active smokers $^{55}$. This data must be a sign of alert and highlights the opportunity that the hospital admission should represent to advance in the process of smoking cessation putting into value the intra-hospital programs for smoking cessation ${ }^{56}$.

The evaluation of the spirometric data in patients admitted for COPD exacerbation is quite alarming. Despite being discharged by senior clinicians in specialty hospitals, 69\% of the cases discharged with a diagnosis of COPD exacerbation had no spirometry in their medical history (Fig. 5A). More strikingly, 13.5\% of the registered spirometries did not show an obstructive pattern (Fig. 5B). These cases cannot 


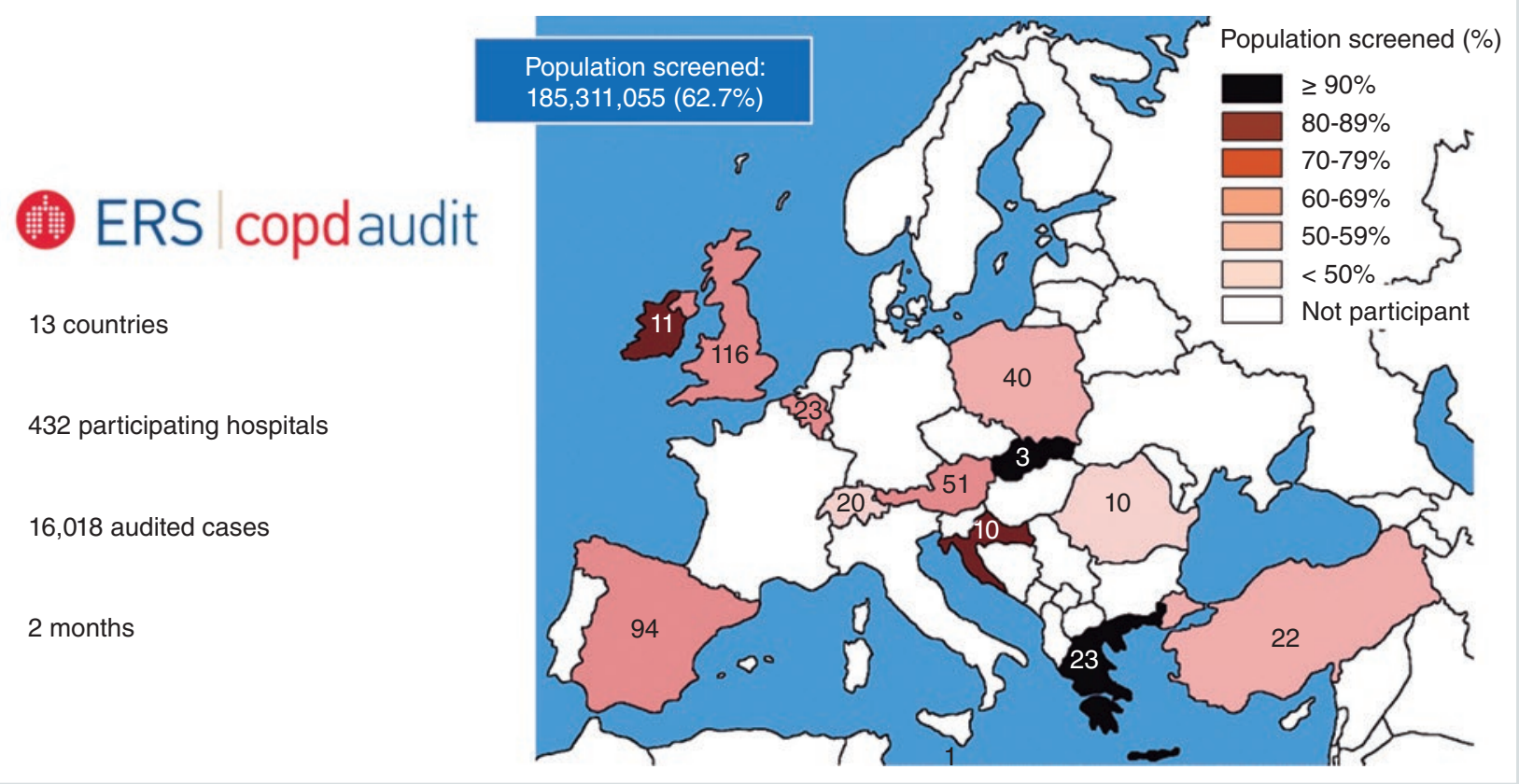

FIgUre 3. Participating countries with number of centres in the European COPD Audit.

be diagnosed of COPD and should therefore not have been discharged with a diagnosis of exacerbation of COPD. The data open two important debates: on the one hand, there is a need to have the diagnosis of COPD secured before giving a diagnosis of exacerbation; on the other hand, assuming that a number of patients who are admitted to hospital do not have a pre-admission study, hospitalisation could be established as an opportunity to confirm this diagnosis. Although this may seem controversial, a recent study conducted in Spain assessed the role of spirometry performed during admission the day before discharge from hospital ${ }^{57}$. The authors found that a considerable number of patients did not go to the follow-up visit after admission and that pre-discharge spirometry could change severity with respect to follow-up, but it did not change the diagnosis of airflow limitation ${ }^{57}$. In this sense, the debate on the usefulness of pre-discharge spirometry is not closed as yet.

Regarding therapies for the exacerbation, the European COPD Audit revealed two key areas for improvement. The first is related to the use of pulmonary rehabilitation programs after admission. According to the European data, only $50.2 \%$ of cases received this type of treatment after discharge (Fig. 6A). However, there is currently consistent evidence showing that pulmonary rehabilitation after exacerbations reduces re-admissions, hospital stay and mortality ${ }^{58}$. Interestingly, Spain is at the level of other countries that are not in our geographical environment of pulmonary rehabilitation availability (Fig. 6A). These differences between countries are likely to be related to the unequal distribution of resources in 


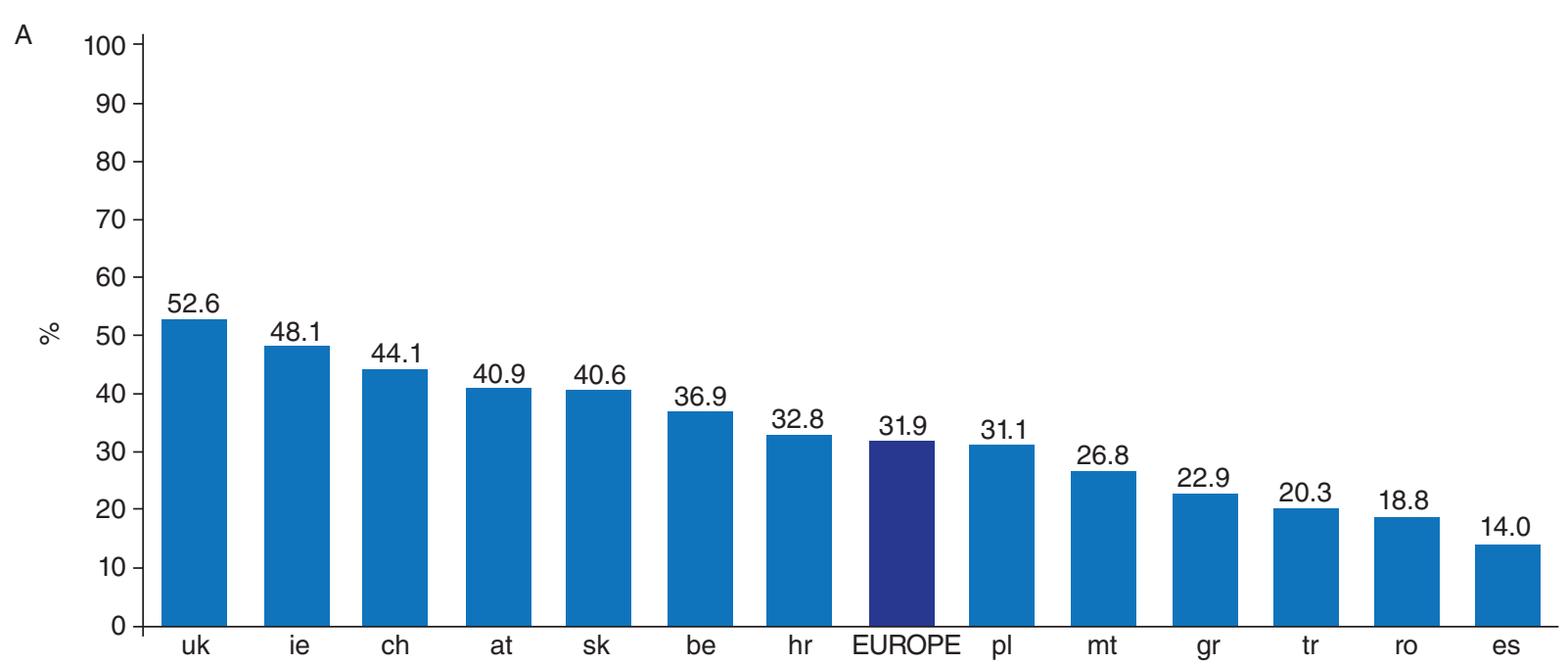

B

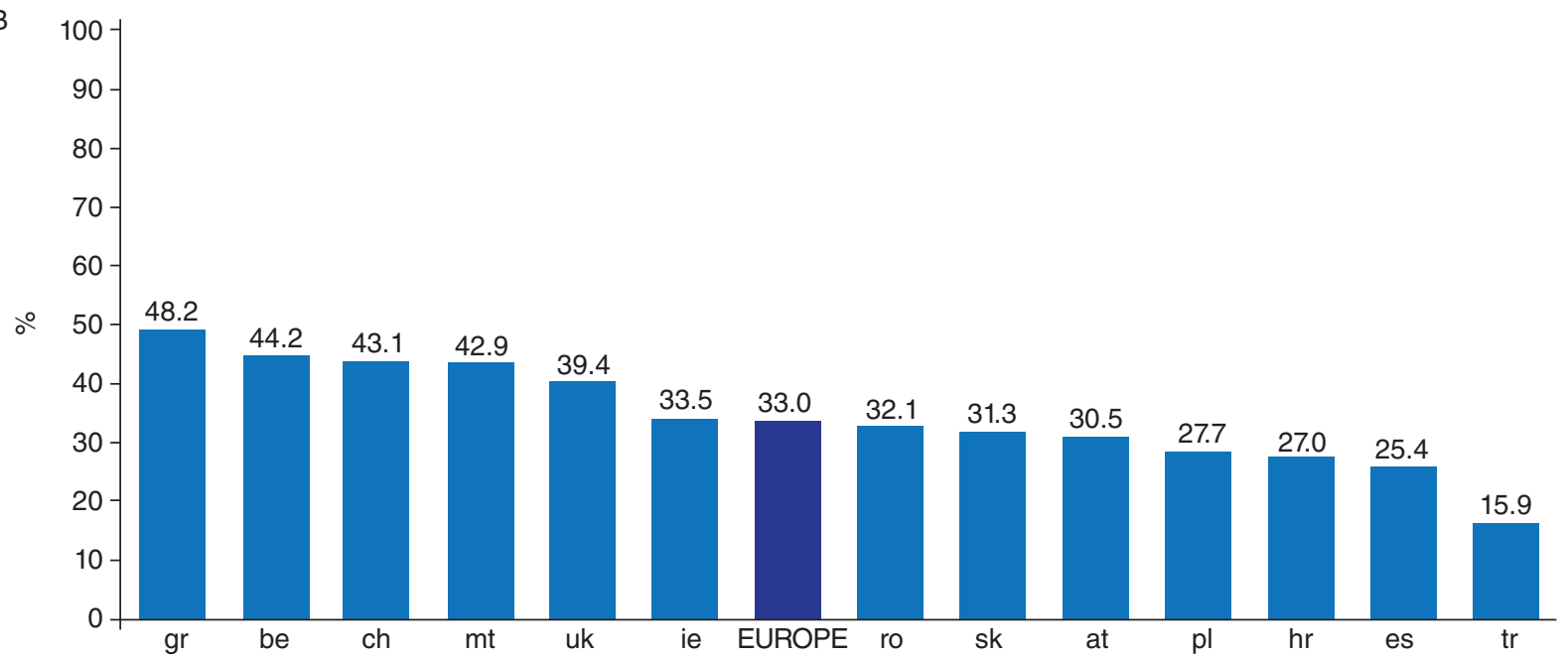

Figure 4. Percentage of women (A) and current smokers (B) admitted to hospital in the different participating countries in the European COPD Audit. Each country is identified by their internet notation in light blue. Dark blue represents the European average.

at: Austria; be: Belgium; ch: Switzerland; es: Spain; gr: Greece; hr: Croatia; ie: Ireland; mt: Malta; pl: Poland; ro: Romania; sk: Slovakia; tr: Turkey; uk: United Kingdom.

pulmonary rehabilitation in Europe as evidenced by a survey carried out by the network of European COPD audit centres ${ }^{59}$.

The second aspect that needs to be stressed is the use of non-invasive ventilation in patients with acute hypercapnic respiratory failure with respiratory acidosis (Fig. 6B). According to the
European audit data, this treatment was applied in $46 \%$ of the cases in which it was indicated. This figure is worrisome. For decades, consistent evidence of the clinical impact of non-invasive ventilation in these patients has been clear, describing benefits in number of intubations, hospital stay, intensive care units admissions and mortality ${ }^{60,61}$. The analysis of the reasons for 


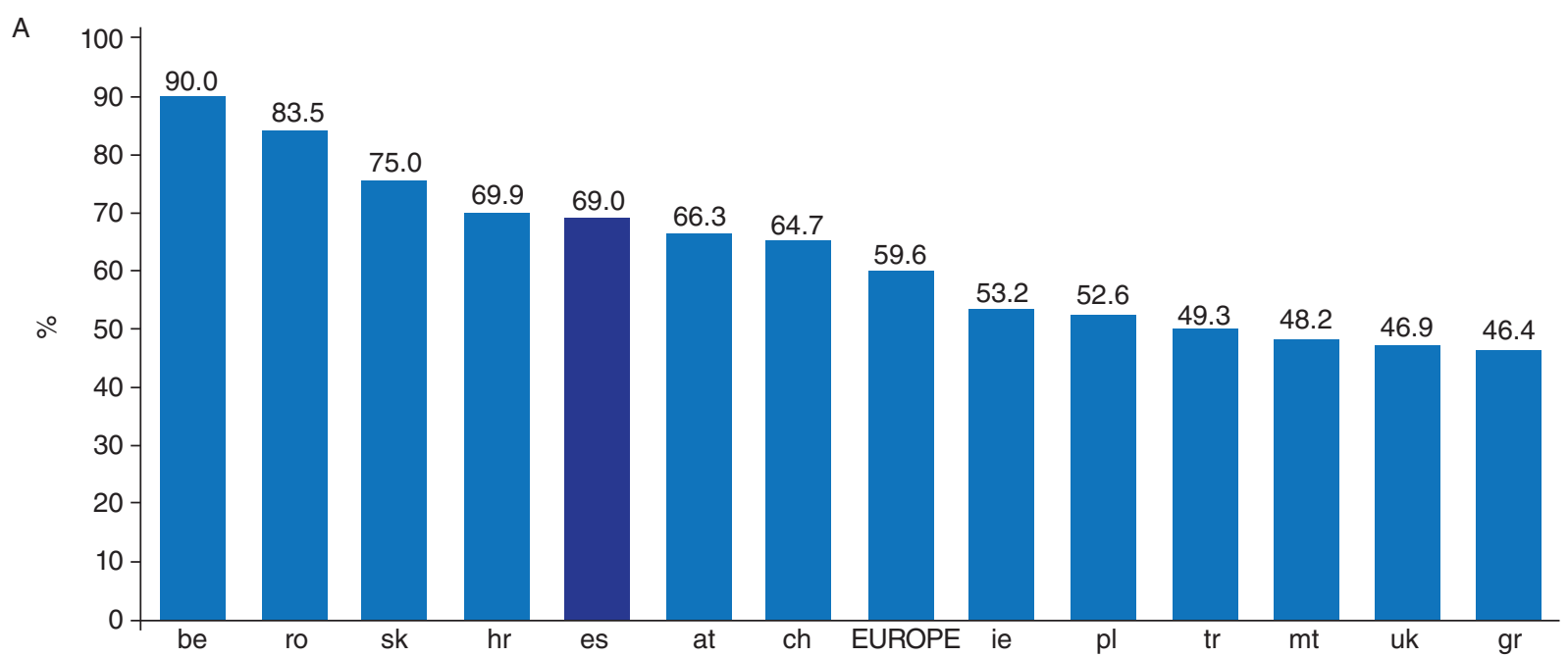

B

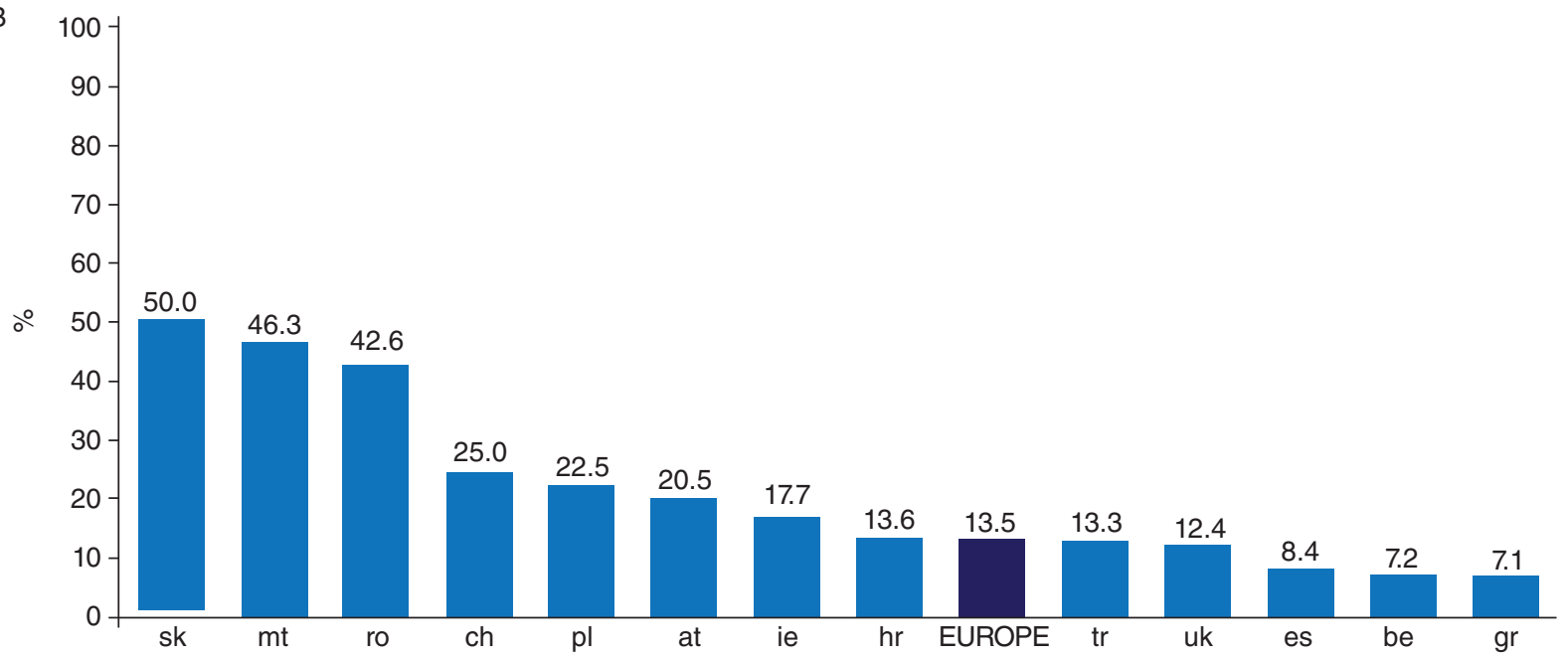

Figure 5. Percentage of cases with available spirometry (A) and those without an obstructive spirometric pattern (B) admitted to hospital in the different participating countries in the European COPD Audit. Each country is identified by their internet notation in light blue. Dark blue represents the European average.

For other abbreviations, see Figure 4.

this under-utilisation exceeds the objectives of this article, but this phenomenon has been described in previous studies and its clinical consequences are evident ${ }^{62}$. Respiratory intermediate care units have been proposed as the one solution for the evaluation and treatment of these patients with a significant positive clinical impact ${ }^{63}$.

\section{Clinical audits for chronic obstructive pulmonary disease outpatient care}

Although there have been numerous initiatives that assess various aspects of outpatient COPD care, formal clinical audits have been smaller in number at this setting. In Spain, a first pilot clinical audit was conducted in Andalusia between 


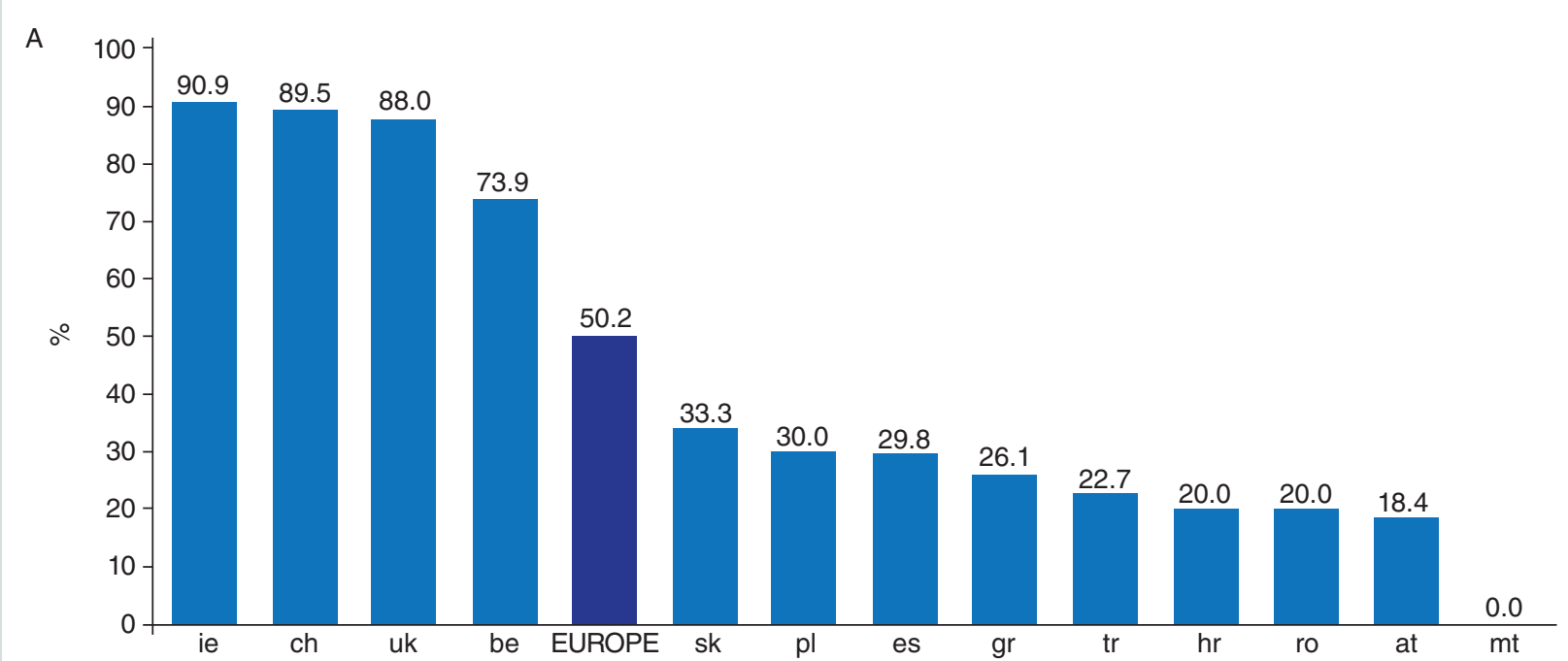

B

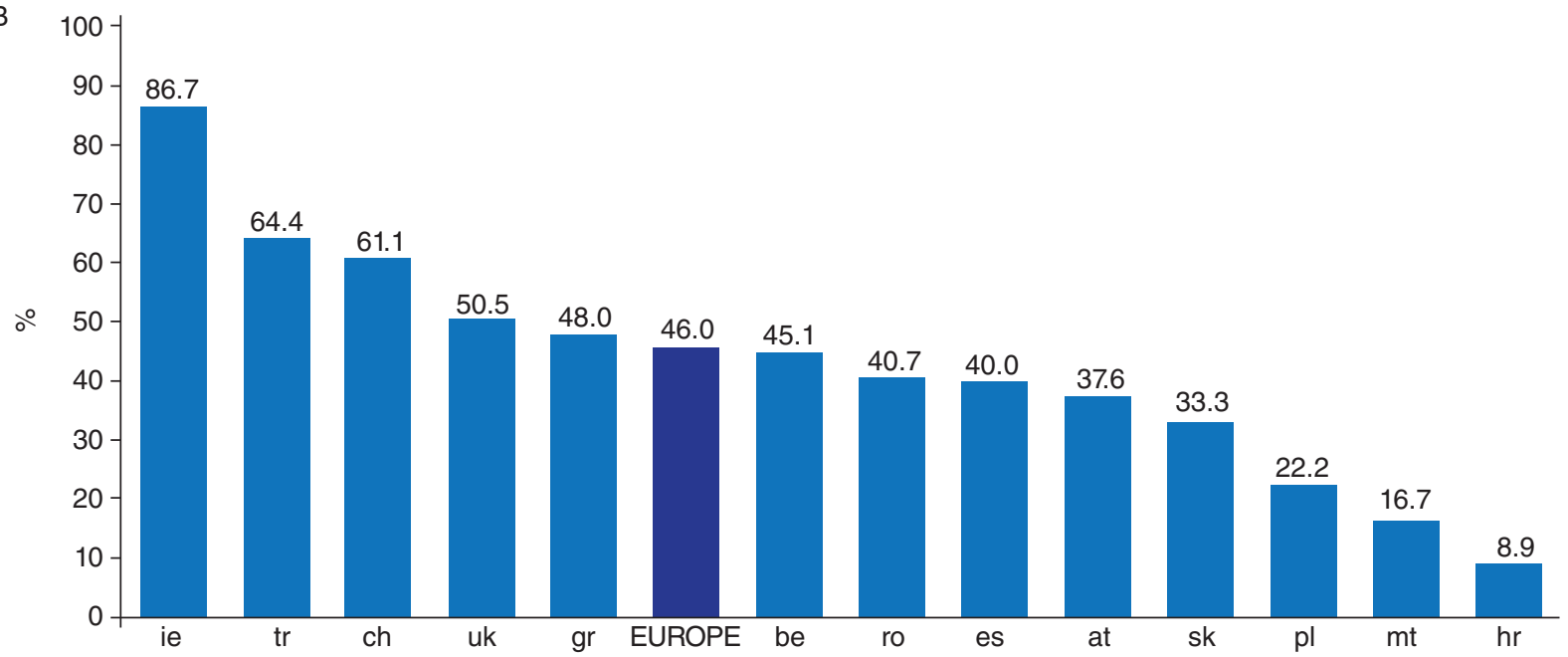

FiguRE 6. Percentage of cases receiving pulmonary rehabilitation after discharge (A) and those receiving non-invasive ventilation and $\mathrm{pH}<7.35$ (B) admitted to hospital in the different participating countries in the European COPD Audit. Each country is identified by their internet notation in light blue. Dark blue represents the European average.

For other abbreviations, see Figure 4.

2013 and 2014 and assessed ambulatory clinical care in 621 clinical records from 9 hospitals $^{64}$. This audit was followed by two major national studies. The EPOCONSUL study, an observational cross-sectional study with prospective case recruitment in outpatient respiratory clinics, audited 4508 medical records between 2014 and $2015^{65}$ and the DEsign and Local Implementation of Clinical Audits in different Types of Obstructive lung diseases (DELICATO) study evaluated 2551 records during the same period of time, providing an innovative perspective according to the fragility of the case. 
These studies have provided information on different key aspects regarding clinical care including: an evaluation of the adherence to clinical practice guidelines and a study of their variability ${ }^{26,65-67}$, they have helped us to understand the determinants guiding the clinical decisions of stepping up and down treatment in stable COPD ${ }^{68,69}$, they have allowed us to evaluate changes in clinical practice in relation to annual seasonality ${ }^{70,71}$, as well as to make specific evaluations of specific clinical scenarios ${ }^{25}$. Altogether, a list of strengths and weaknesses of clinical care for COPD outpatients can be obtained (Table 1).

\section{Clinical audits for primary care}

The information regarding how COPD patients are treated in the primary care setting is essential and would provide very relevant information on the process of care. It might also reveal the key areas wherein improvements are required in order to complete the picture obtained in secondary care audits. Therefore, formal clinical audits in primary care are emerging to evaluate clinical performance in this setting using a standardised methodology $\mathrm{y}^{53}$. Additionally, although not formally labelled as clinical audits, previous analyses have been done describing different aspects of clinical performance in primary care using different methodological approaches ${ }^{72-74}$.

The Community Assessment of COPD Health Care (COACH) study was an observational multicentre national randomised non-interventional clinical audit aimed at evaluating clinical practice delivered to COPD patients in primary care in Spain ${ }^{24}$. The results of this study indicate that there is considerable variability in clinical performance that cannot completely be attributed to the severity of the disease. Notably, most evaluated parameters were judged to fall under inadequate performance, except two (i.e. registration of influenza vaccination, and registration of exacerbations in the previous years), that were considered excellent.

In addition, $\mathrm{COACH}$ investigated $\mathrm{COPD}$ diagnosis in primary care, quantifying the degree of inaccurate diagnosis and assessing the associated factors at patient and primary care centre level ${ }^{24}$. As a result, the degree of accurate diagnosis in primary care was as low as $17.6 \%$. Variables related to smoking status, lung function assessment, and some specific interventions were considered associated with an inaccurate diagnosis at the patient level. Additionally, complementary tests availability and different aspects of the resources available, like the presence of primary care trainees, the availability of a tobacco cessation unit or home nebulised therapy were also associated with inaccurate diagnosis at the centre level.

A recent review highlighted the possible clinical situations in which an inaccurate diagnosis of COPD could occur ${ }^{75}$. On the one hand, receiving inadequate healthcare ${ }^{76}$, or suffering from an uncontrolled disease that may also impact on other comorbidities ${ }^{77}$ are some of the consequences of under-diagnosis. On the other hand, over-diagnosis is another problem that frequently occurs in COPD. This over-diagnosis can impact on several key aspects of the disease ${ }^{78}$, including an increased exposure to not-otherwise-needed pharmacological treatment, an increase in health services use for the wrong patients, and the performance of a number of diagnostic tests. 
TABLE 1. Strengths and weaknesses of the COPD outpatient clinical care in Spain

\begin{tabular}{|c|c|c|}
\hline & Appropriate measures & Measures to improve \\
\hline Anamnesis & $\begin{array}{l}\text { - Record dyspnoea grade } \\
\text { - Record respiratory symptoms } \\
\text { - Exacerbation risk evaluation }\end{array}$ & $\begin{array}{l}\text { - Record of physical activity } \\
\text { - COPD Assessment Test use }\end{array}$ \\
\hline Complementary & $\begin{array}{l}\text { - Simple radiology evaluation } \\
\text { - Spirometry evaluation }\end{array}$ & $\begin{array}{l}\text { - Alpha-1 antitrypsin determination } \\
\text { - Quantification of emphysema by computed tomography } \\
\text { - Cardiopulmonary exercise test }\end{array}$ \\
\hline Diagnosis & - Correct diagnosis done & $\begin{array}{l}\text { - GesEPOC phenotype } \\
\text { - GOLD classification } \\
\text { - Use of BODE/BODEx indexes }\end{array}$ \\
\hline Treatment & $\begin{array}{l}\text { - Use long-term bronchodilators } \\
\text { - Tobacco recommendations } \\
\text { - Exact dose of inhalers recorded }\end{array}$ & $\begin{array}{l}\text { - Flu vaccine recommendation } \\
\text { - Pneumococcal vaccine recommendation } \\
\text { - Exercise recommendation } \\
\text { - Adherence evaluation } \\
\text { - Adverse effects evaluation }\end{array}$ \\
\hline
\end{tabular}

BODE index: Body-mass index, airflow Obstruction, Dyspnoea, and Exercise; BODEx index: BODE and severe Exacerbations; COPD: chronic obstructive pulmonary disease; GesEPOC: Spanish COPD guidelines; GOLD: Global initiative for chronic Obstructive Lung Disease.

Additionally, people may be urged to adapt their lives for a disease they do not have, with regular unneeded monitoring which finally labels them as sick people. Finally, it clearly impacts on the health system leading to potential extra costs.

This scenario is clearly influenced by the availability and performance of spirometry in primary care. The latter investigation in a stable clinical situation, at rest, and with a bronchodilator test is essential to confirm the diagno$\operatorname{sis}^{79}$. Unfortunately, the confirmation of this diagnostic criterion in primary care is far from optimal in Spain. A study conducted in Spain evaluated the availability and frequency of performing spirometry in primary care in Spain ${ }^{80}$. The study revealed that most health centres had a spirometer. However, the frequency of performing spirometries was 5.6 per week with a range between regions of 2.0 to 8.8 spirometries per week for the study of airway diseases. Considering the prevalence of COPD, asthma and bronchiectasis, the three main chronic airway diseases by frequency, it can clearly be concluded that the frequency of spirometry in primary care remains insufficient.

\section{CONCLUSIONS}

Clinical audits emerge as an overarching tool that aims to improve healthcare. Far from being merely a systematised procedure for retrospective recovery of clinical data and the available resources for evaluating professional performance and associated factors, clinical audits are a dynamic, continuous updating process that gives feedback and has the ultimate goal of improving healthcare.

Previous audit studies have shown two main learning points. First, auditing is possible. Despite the initial apparent complexity that implies having to work with different information systems from the different centres and in diverse settings, we and others have shown that it is possible to register and to evaluate the 
healthcare by a clinical audit. Unfortunately, this effort is currently done only in the context of research studies. However, it would be necessary for both clinicians and healthcare managers to understand that auditing should be part of their daily regular clinical work, as is already the case in countries such as the United Kingdom. Today, it is not reasonable that a profession with a high social impact such as medicine does not count on the evaluation and continuous improvement of their professionals performance as part of its daily work.

Second, we can always improve our practice. Although all health professionals involved in the care of the COPD patient provide the best possible care in the context of the resources available, we can always improve. The results of the audits show a hopeful scenario with numerous indicators of excellent healthcare, but also with notable areas of improvement. In the future, clinicians and health managers should work hand in hand so that we can overcome these limitations and provide the best possible clinical care for patients with a chronic disease with high impact for the patients and their families, such as COPD.

\section{ACKNOWLEDGEMENTS}

The authors want to express their gratitude to all the investigators of the clinical audit projects mentioned in the review for their constant and dedicated work in the collection and cleaning of the data and without whose commendable work these projects would not have been possible. They also want to thank the funding agencies, both public and private, for having believed in this work philosophy based on continuous improvement.
This article has been written without external funding. However, the clinical audit studies mentioned here have received funding and support from both public agencies, through the Carlos III Health Institute (FIS projects PI08/90129, PI07/90129, PI07/90309, PI07/90486, PI07/90503, PI07/90516, PI07/90721, PI08/90129, PI08/90578, PI08/90251, PI08/90529, PI07/90403, PI08/90447, PI08/90457, PI08/90486, PI08/90550 and PI13/01993) and the Network Biomedical Research Center in Respiratory Diseases (CIBERES), and private organisations, through Boehringer Ingelheim, Menarini, the Spanish Society of Pulmonology and Thoracic Surgery (SEPAR) and the European Respiratory Society (ERS).

\section{DISCLOSURE}

Dr. Lopez-Campos reports grants, personal fees and non-financial support from: GSK, Menarini, Grifols, Rovi, Novartis, Chiesi, Boehringer, Ferrer, Bial, Esteve, AstraZeneca, Gebro Farma, and Teva; outside the submitted work. Dr. Abad Arranz and Dr. Carrasco Hernández have nothing to disclose.

\section{REFERENCES}

1. Collaborators GBDCoD. Global, regional, and national age-sex-specific mortality for 282 causes of death in 195 countries and territories, 1980-2017: a systematic analysis for the Global Burden of Disease Study 2017. Lancet. 2018; 392:1736-88.

2. Buist AS, McBurnie MA, Vollmer WM et al. International variation in the prevalence of COPD (the BOLD Study): a population-based prevalence study. Lancet. 2007;370:741-50.

3. Montes de Oca M, Lopez Varela MV, Acuna A et al. ALAT-2014 Chronic Obstructive Pulmonary Disease (COPD) Clinical Practice Guidelines: questions and answers. Arch Bronconeumol. 2015;51:403-16.

4. Miravitlles M. What was the impact of the Spanish COPD guidelines (GesEPOC) and how can they be improved? Arch Bronconeumol. 2016:52: 1-2.

5. Soler-Cataluna JJ, Calle M, Cosio BG et al. [Health-care quality standards in chronic obstructive pulmonary disease]. Arch Bronconeumol. 2009;45:1 96-203. 
6. Miravitlles M, Soriano JB, Garcia-Rio F et al. Prevalence of COPD in Spain: impact of undiagnosed COPD on quality of life and daily life activities. Thorax. 2009;64:863-8

7. Raghavan D, Varkey A, Bartter T. Chronic obstructive pulmonary disease: the impact of gender. Curr Opin Pulm Med. 2017;23:117-23.

8. Salari-Moghaddam A, Milajerdi A, Larijani B, Esmaillzadeh A. Processed red meat intake and risk of COPD: A systematic review and dose-response meta-analysis of prospective cohort studies. Clin Nutr. 2018.

9. Kaluza J, Harris H, Linden A, Wolk A. Long-term unprocessed and processed red meat consumption and risk of chronic obstructive pulmonary disease: a prospective cohort study of women. Eur J Nutr. 2018.

10. Kaluza J, Harris HR, Linden A, Wolk A. Long-term consumption of fruits and vegetables and risk of chronic obstructive pulmonary disease: a prospective cohort study of women. Int J Epidemiol. 2018;47:1897-1909.

11. Kang J, Kim KT, Lee JH et al. Predicting treatable traits for long-acting bronchodilators in patients with stable COPD. Int J Chron Obstruct Pulmon Dis. 2017;12:3557-65.

12. de Jong K, Vonk JM, Imboden $\mathrm{M}$ et al. Genes and pathways underlying susceptibility to impaired lung function in the context of environmental tobacco smoke exposure. Respir Res. 2017:18:142.

13. Bui DS, Lodge CJ, Burgess JA et al. Childhood predictors of lung function trajectories and future COPD risk: a prospective cohort study from the first to the sixth decade of life. Lancet Respir Med. 2018;6:535-44.

14. Kinney GL, Santorico SA, Young KA et al. Identification of Chronic Obstructive Pulmonary Disease Axes That Predict All-Cause Mortality: The COPDGene Study. Am J Epidemiol. 2018;187:2109-16.

15. Cardoso J, Coelho R, Rocha C et al. Prediction of severe exacerbations and mortality in COPD: the role of exacerbation history and inspiratory capacity/ total lung capacity ratio. Int J Chron Obstruct Pulmon Dis. 2018;13: 1105-13.

16. Guerra B, Haile SR, Lamprecht B et al. Large-scale external validation and comparison of prognostic models: an application to chronic obstructive pulmonary disease. BMC Med. 2018;16:33.

17. Lytras T, Kogevinas M, Kromhout $\mathrm{H}$ et al. Occupational exposures and 20-year incidence of COPD: the European Community Respiratory Health Survey. Thorax. 2018;73:1008-15.

18. Jo YS, Lim MN, Han YJ, Kim WJ. Epidemiological study of PM2.5 and risk of COPD-related hospital visits in association with particle constituents in Chuncheon, Korea. Int J Chron Obstruct Pulmon Dis. 2018;13:299-307.

19. Grady ST, Koutrakis P, Hart JE et al. Indoor black carbon of outdoor origin and oxidative stress biomarkers in patients with chronic obstructive pulmonary disease. Environ Int. 2018:115:188-95.

20. Romley JA, Jena AB, Goldman DP. Hospital spending and inpatient mortality: evidence from California: an observational study. Ann Intern Med. 2011: 154:160-7.

21. Needleman J, Buerhaus P, Pankratz VS et al. Nurse staffing and inpatient hospital mortality. N Engl J Med. 2011:364:1037-45.

22. Kruk ME, Gage AD, Joseph NT et al. Mortality due to low-quality health systems in the universal health coverage era: a systematic analysis of amenable deaths in 137 countries. Lancet. 2018;392:2203-12.

23. Lipari M, Smith AL, Kale-Pradhan PB, Wilhelm SM. Adherence to GOLD Guidelines in the Inpatient COPD Population. J Pharm Pract. 2018;31:29-33.

24. Abad-Arranz M, Moran-Rodriguez A, Mascaros Balaguer E et al. Community Assessment of COPD Health Care (COACH) study: a clinical audit on primary care performance variability in COPD care. BMC Med Res Methodol. 2018;18:68.

25. Calle Rubio M, Soriano JB, Lopez-Campos JL et al. Testing for alpha-1 antitrypsin in COPD in outpatient respiratory clinics in Spain: A multilevel, cross-sectional analysis of the EPOCONSUL study. PLoS One. 2018;13: e0198777.

26. Lopez-Campos JL, Abad Arranz M, Calero-Acuna C et al. Guideline Adherence in Outpatient Clinics for Chronic Obstructive Pulmonary Disease: Results from a Clinical Audit. PLoS One. 2016;11:e0151896.

27. Pozo-Rodriguez F, Castro-Acosta A, Alvarez CJ et al. Determinants of between-hospital variations in outcomes for patients admitted with COPD exacerbations: findings from a nationwide clinical audit (AUDIPOC) in Spain. Int J Clin Pract. 2015;69:938-47.
28. Merlo J, Chaix B, Ohlsson H et al. A brief conceptual tutorial of multilevel analysis in social epidemiology: using measures of clustering in multilevel logistic regression to investigate contextual phenomena. J Epidemiol Community Health. 2006;60:290-7.

29. Karthikeyan G, Pais P. Clinical judgement \& evidence-based medicine: time for reconciliation. Indian J Med Res. 2010;132:623-6.

30. Accad M, Francis D. Does evidence based medicine adversely affect clinical judgment? BMJ. 2018:362:k2799.

31. Burkle T, Denecke K, Lehmann M et al. Integrated Care Processes Designed for the Future Healthcare System. Stud Health Technol Inform. 2017;245:20-4.

32. Segato F, Masella C. Integrated care in action: opening the "black box" of implementation. Int J Health Plann Manage. 2017;32:50-71.

33. Kirst M, Im J, Burns $\mathrm{T}$ et al. What works in implementation of integrated care programs for older adults with complex needs? A realist review. Int J Qual Health Care; 2017:29:612-24.

34. Yeoh EK, Wong MCS, Wong ELY et al. Benefits and limitations of implementing Chronic Care Model (CCM) in primary care programs: A systematic review. Int J Cardiol. 2018;258:279-88.

35. Hernandez C, Alonso A, Garcia-Aymerich J et al. Integrated care services: lessons learned from the deployment of the NEXES project. Int J Integr Care 2015:15:e006.

36. Ray-Barruel G, Ullman AJ, Rickard CM, Cooke M. Clinical audits to improve critical care: Part 2: Analyse, benchmark and feedback. Aust Crit Care. 2018 31:106-9.

37. Ullman AJ, Ray-Barruel G, Rickard CM, Cooke M. Clinical audits to improve critical care: Part 1 Prepare and collect data. Aust Crit Care. 2018;31:101-5

38. Flottorp SA, Jamtvedt G, Gibis B, McKee M. Using audit and feedback to health professionals to improve the quality and safety of health care. WHO Regional office for Europe, Copenhagen, 2010.

39. Cousson PY, Decerle N, Munoz-Sanchez ML et al. The "Plan" phase of a Deming cycle: Measurement of quality and outcome of root canal treatments in a university hospital. Eur J Dent Educ. 2019;23:e1-e11.

40. Disease GBD, Injury I, Prevalence C. Global, regional, and national incidence, prevalence, and years lived with disability for 328 diseases and injuries for 195 countries, 1990-2016: a systematic analysis for the Global Burden of Disease Study 2016. Lancet. 2017:390:1211-59.

41. Lopez-Campos JL, Ruiz-Ramos M, Soriano JB. Mortality trends in chronic obstructive pulmonary disease in Europe, 1994-2010: a joinpoint regression analysis. Lancet Respir Med. 2014:2:54-62.

42. Soriano JB, Rojas-Rueda D, Alonso J et al. The burden of disease in Spain Results from the Global Burden of Disease 2016. Med Clin (Barc). 2018;151 171-90.

43. Foo J, Landis SH, Maskell J et al. Continuing to Confront COPD International Patient Survey: Economic Impact of COPD in 12 Countries. PLoS One. 2016;11:e0152618.

44. Roberts CM, Ryland I, Lowe D et al. Audit of acute admissions of COPD standards of care and management in the hospital setting. Eur Respir J. 2001, 17:343-9.

45. Pozo-Rodriguez F, Alvarez CJ, Castro-Acosta A et al. [Clinical audit of patient admitted to hospital in Spain due to exacerbation of COPD (AUDIPOC study): method and organisation]. Arch Bronconeumol. 2010;46:349-57.

46. Lopez-Campos JL, Asensio-Cruz MI, Castro-Acosta A et al. Results from an audit feedback strategy for chronic obstructive pulmonary disease in-hospital care: a joint analysis from the AUDIPOC and European COPD audit studies. PLoS One. 2014;9:e110394.

47. Liaaen ED, Henriksen AH, Stenfors N. A Scandinavian audit of hospitalizations for chronic obstructive pulmonary disease. Respir Med. 2010;104:1304-9.

48. Agabiti N, Belleudi V, Davoli M et al. Profiling hospital performance to monitor the quality of care: the case of COPD. Eur Respir J. 2010;35:1031-8.

49. Pretto JJ, McDonald VM, Wark PA, Hensley MJ. Multicentre audit of inpatient management of acute exacerbations of chronic obstructive pulmonary disease: comparison with clinical guidelines. Intern Med J. 2012;42:380-7.

50. Lopez-Campos JL, Hartl S, Pozo-Rodriguez F et al. European COPD Audit: design, organisation of work and methodology. Eur Respir J. 2013;41:270-6. 
51. Roberts CM, Lopez-Campos JL, Pozo-Rodriguez F et al. European hospital adherence to GOLD recommendations for chronic obstructive pulmonary disease (COPD) exacerbation admissions. Thorax. 2013;68:1169-71.

52. Lopez-Campos JL, Hartl S, Pozo-Rodriguez F et al. Variability of hospital resources for acute care of COPD patients: the European COPD Audit. Eur Respir J. 2014;43:754-62.

53. Fisk M, McMillan V, Brown J et al. Inaccurate diagnosis of COPD: the Welsh National COPD Audit. Br J Gen Pract. 2019;69:e1-e7.

54. Pirie K, Peto R, Reeves GK et al. The 21st century hazards of smoking and benefits of stopping: a prospective study of one million women in the UK. Lancet. 2013;381:133-41.

55. Regan S, Viana JC, Reyen M, Rigotti NA. Prevalence and predictors of smoking by inpatients during a hospital stay. Arch Intern Med. 2012;172: 1670-74.

56. Henoch I, Lofdahl CG, Ekberg-Jansson A. Influences of patient education on exacerbations and hospital admissions in patients with COPD - a longitudinal national register study. Eur Clin Respir J. 2018;5:1500073.

57. Fernandez-Villar A, Represas-Represas C, Mouronte-Roibas C et al. Reliability and usefulness of spirometry performed during admission for COPD exacerbation. PLoS One. 2018;13:e0194983.

58. Ryrso CK, Godtfredsen NS, Kofod LM et al. Lower mortality after early supervised pulmonary rehabilitation following COPD-exacerbations: a systematic review and meta-analysis. BMC Pulm Med. 2018;18:154.

59. Spruit MA, Pitta F, Garvey C et al. Differences in content and organisational aspects of pulmonary rehabilitation programmes. Eur Respir J. 2014; 43:1326-37.

60. Fernandez Guerra J, Lopez-Campos Bodineau JL, Perea-Milla Lopez E et al. [Non invasive ventilation for acute exacerbation of chronic obstructive pulmonary disease: a meta-analysis]. Med Clin (Barc). 2003;120:281-6.

61. Shah NM, D'Cruz RF, Murphy PB. Update: non-invasive ventilation in chronic obstructive pulmonary disease. J Thorac Dis. 2018;10(Suppl 1): S71-79.

62. Ozsancak Ugurlu A, Habesoglu MA. Epidemiology of NIV for Acute Respiratory Failure in COPD Patients: Results from the International Surveys vs. the "Real World". COPD. 2017;14:429-38.

63. Plate JDJ, Leenen LPH, Houwert M, Hietbrink F. Utilisation of Intermediate Care Units: A Systematic Review. Crit Care Res Pract. 2017. 2017;8038460.

64. Lopez-Campos JL, Abad Arranz M, Calero Acuna C et al. Clinical Audits in Outpatient Clinics for Chronic Obstructive Pulmonary Disease: Methodological Considerations and Workflow. PLoS One. 2015;10:e0141856.

65. Calle Rubio M, Alcazar Navarrete B, Soriano JB et al. Clinical audit of COPD in outpatient respiratory clinics in Spain: the EPOCONSUL study. Int J Chron Obstruct Pulmon Dis. 2017;12:417-26.

66. Calle Rubio M, Lopez-Campos JL, Soler-Cataluna JJ et al. Variability in adherence to clinical practice guidelines and recommendations in COPD outpatients: a multi-level, cross-sectional analysis of the EPOCONSUL study. Respir Res. 2017;18:200.

67. Calle Rubio M, Rodriguez Hermosa JL, Soler-Cataluna JJ et al. Medical Care According to Risk Level and Adaptation to Spanish COPD Guidelines (Gesepoc): The Epoconsul Study. Arch Bronconeumol. 2018;54:270-9.

68. Lopez-Campos JL, Navarrete BA, Soriano JB et al. Determinants of medical prescriptions for COPD care: an analysis of the EPOCONSUL clinical audit. Int J Chron Obstruct Pulmon Dis. 2018;13:2279-88.

69. Lopez-Campos JL, Abad Arranz M, Calero Acuna C et al. Determinants for changing the treatment of COPD: a regression analysis from a clinical audit. Int J Chron Obstruct Pulmon Dis. 2016;11:1171-8.

70. Lopez-Campos JL, Abad Arranz M, Calero-Acuna C et al. Seasonal variability in clinical care of COPD outpatients: results from the Andalusian COPD audit. Int J Chron Obstruct Pulmon Dis. 2017;12:785-92.

71. Lopez-Campos JL, Calero C, Quintana-Gallego E. Symptom variability in COPD: a narrative review. Int J Chron Obstruct Pulmon Dis. 2013;8:231-8.

72. Lundell S, Tistad M, Rehn B et al. Building COPD care on shaky ground: a mixed methods study from Swedish primary care professional perspective. BMC Health Serv Res. 2017;17:467.

73. Rothnie KJ, Chandan JS, Goss HG et al. Validity and interpretation of spirometric recordings to diagnose COPD in UK primary care. Int J Chron Obstruct Pulmon Dis. 2017;12:1663-8.

74. Gruffydd-Jones K, Brusselle G, Jones R et al. Changes in initial COPD treatment choice over time and factors influencing prescribing decisions in UK primary care: in UK primary care: a real-world, retrospective, observational. NPJ Prim Care Respir Med. 2016;26:16002.

75. Fernandez-Villar A, Soriano JB, Lopez-Campos JL. Overdiagnosis of COPD precise definitions and proposals for improvement. Br J Gen Pract. 2017:67: 183-4.

76. Soriano JB, Zielinski J, Price D. Screening for and early detection of chronic obstructive pulmonary disease. Lancet. 2009;374:721-32.

77. Putcha N, Drummond MB, Wise RA, Hansel NN. Comorbidities and Chronic Obstructive Pulmonary Disease: Prevalence, Influence on Outcomes, and Management. Semin Respir Crit Care Med. 2015;36:575-91.

78. Colak Y, Afzal S, Nordestgaard BG et al. Prognosis of asymptomatic and symptomatic, undiagnosed COPD in the general population in Denmark: a prospective cohort study. Lancet Respir Med. 2017;5:426-34.

79. Miravitlles M, Soler-Cataluna JJ, Calle M et al. Spanish Guidelines for Management of Chronic Obstructive Pulmonary Disease (GesEPOC) 2017. Pharmacological Treatment of Stable Phase. Arch Bronconeumol. 2017;53 324-35.

80. Lopez-Campos JL, Soriano JB, Calle M. Encuesta de Espirometria en Espana P. A comprehensive, national survey of spirometry in Spain: current bottlenecks and future directions in primary and secondary care. Chest. 2013; 144:601-9. 